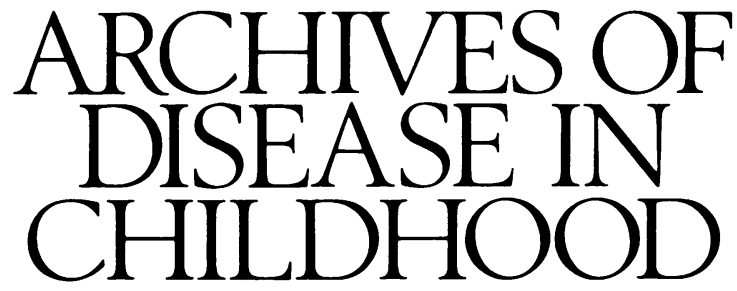

The fournal of the British Paediatric Association

\title{
Annotations
}

\section{Why block a small hole? The adverse effects of nasogastric tubes}

With the onset of winter and the season of respiratory syncytial virus infections it is timely to reconsider what is known about the adverse role of nasogastric tubes on respiratory function in infants and small children. The ability to gavage feed infants has enabled hydration and nutrition to be maintained without the need for intravenous access or intravenous feeding. However, the presence of a nasogastric feeding tube in a breathless infant compromises a small airway at a time when patency is most needed. The nasal and oral route to the stomach each have advantages, although the former will rarely benefit a child with respiratory distress.

The narrowest portion of the airway, accounting for most of the nasal resistance, is the anterior nasal valve which lies just behind the nares. Anatomically it consists of the lower edge of the upper lateral cartilage, the anterior end of the inferior turbinate, the adjacent nasal septum together with the surrounding soft tissues. ${ }^{1}$ Physiologically it is less well defined, altering in size depending on the nasal cycle of alternating mucosal swelling, and is capable of collapsing on forced inspiration. Polgar and Kong measured nasal resistance to airflow in infants and found it contributed on average $40 \%$ of the infants total lung resistance, ${ }^{2}$ similar to the $50 \%$ it contributes to an adults total lung resistance. In absolute terms this was five times greater than that of adults. Studies in adults have shown that the nasal resistance is variable and that voluntary flaring of the alar margins can also decrease nasal airway resistance by $21 \%$ whereas constriction increases this by $67 \%{ }^{3}$ There are also genetic differences in nasal resistance which is lowest in black adults. ${ }^{4}$ The size of the anterior nasal valves determines whether air flow is turbulent or not, and with it the resistance and consequently the work of respiration rises exponentially. There are few studies of the exact dimension of the nasal air passage in infants, however, an indication of the maximal airway diameter can be obtained from the size of nasotracheal tubes used in infants. A $3 \mathrm{~mm}$ nasotracheal tube (external diameter $4.2 \mathrm{~mm}$ ) has a cross sectional area of $13.8 \mathrm{~mm}^{2}$ and is a snug fit in the majority of term infants. A 6 French (FG) (1 unit $\sim 0.33 \mathrm{~mm}$ ) feeding catheter has a cross sectional area of $3.1 \mathrm{~mm}^{2}$ and would apparently only partially block an airway of this size. However, the presence of a nasogastric tube results in mucosal oedema and secretion build up which would further narrow the nasal airway. Stocks measured the effect of this nasal obstruction in preterm infants and found a $50 \%$ increase in total airway resistance when a smaller 5 FG tube was passed through the largest nostril and a 30\% increase when passed through the smaller nostril. ${ }^{5}$ The absolute change in airway resistance was greatest in white infants. Other workers have shown that newborn infants less than $2000 \mathrm{~g}$ in weight have measurable pulmonary compromise with nasogastric tubes, ${ }^{6}$ more periodic breathing, central apnoea, and lower transcutaneous oxygen tension values ${ }^{7}$ when compared with those fed by an orogastric tube.

It is widely believed that infants are obligate nose breathers, solely dependent on the nasal airway for lung ventilation. Indeed infants with bilateral choanal atresia make strenuous but unsuccessful respiratory efforts despite worsening cyanosis, which classically is only relieved when they begin to cry. The main reason for an infant's inability to mouth breathe is that the tongue is relatively large, and is in contact with the palate occluding the oropharynx. In addition the larynx is in a higher position than in older children, placing the epiglottis closer to the palate, enabling the infant to breathe and feed at the same time, but makes mouth breathing more difficult. Recent studies have, however, shown that some infants can successfully breathe through their mouth during sleep, although during oronasal breathing $70 \%$ of the air flow was still through the nasal passages. ${ }^{8}$ The effect of deliberate nasal occlusion has also been studied, with conflicting results. Estimates have suggested that between $10 \%$ and $100 \%$ of infants could initiate mouth breathing. ${ }^{89}$ Fluoroscopic studies of these infants revealed that mouth breathing was achieved by elevation of the soft palate, opening the oropharynx. It is unclear if this is sustained in the majority of infants when the palatal muscles tire. Whereas adults can voluntarily breathe through their mouths to compensate for increased resistance in the lower airway or to reduce the overall work of breathing this would appear a difficult option for the majority of infants.

Children with the most severe bronchiolitis are usually aged between 2 and 6 months - can we extrapolate the results from studies in the newborn to this age group? The relative size of the nasal airway has not increased substantially. They can, however, mouth breathe more readily. There are no studies looking at the effects of nasogastric tubes on respiratory resistance in these sick infants. Infants with bronchiolitis are characteristically tachypnoeic, have over inflated chests, and because they are breathing at high lung volumes are working harder. In addition they have a variable degree of airway obstruction resulting in an increased respiratory resistance and an additional increase in the work of breathing. ${ }^{10}$ Anecdotal 
experience would suggest that any further airway obstruction, further increasing respiratory effort is detrimental, and that removal of a nasogastric tube may prevent the need to ventilate an infant with developing respiratory failure.

The World Health Organisation acute respiratory infection programme includes an inability to feed, as well as the presence of cyanosis, subcostal recession, and increased respiratory rate as criteria for hospitalisation. ${ }^{11}$ In these infants although a nasogastric feeding tube is convenient, their use, especially in white infants, should be questioned. If they are used, Stocks' recommendations are still valid: the smallest tube, passed down the smallest nostril, should be employed and removed before the child deteriorates. Ideally an intravenous infusion should be established. As the first step of resuscitation is to protect the airway - why block it?

The Royal London Hospital,

R SPORIK

Whitechapel,

London E1 $1 B B$

1 Lang J. Clinical anatomy of the nose, nasal cavity and the paranasal sinuses. New York: Thieme Medical Publications, 1989.

2 Polgar G, Kong GP. The nasal resistance of newborn infants. 7 Pediat 1965; 67: 557-67.

3 Rivron RP, Sanderson RJ. The voluntary control of nasal resistance. Rhinology 1991; 29: 181-4.

4 Ohki M, Naito K, Cole P. Dimensions and resistance of the human nose: racial differences. Laryngoscope 1991; 101: 276-8.

5 Stocks J. Effect of nasogastric tubes on nasal resistance during infancy. Arch Dis Child 1980; 55: 17-21.

6 Greenspan JS, Wolfson MR, Holt WJ, Shaffer TH. Neonatal gastric intubation: differential respiratory effects between nasogastric and orogastric tubes. Pediatr Pulmonol 1990; 8: 254-8.

7 van Someren V, Linnett SJ, Stothers JK, Sullivan PG. An investigation into the benefits of resiting nasoenteric feeding tubes. Pediatrics 1984; 74: 379-83.

8 Miller MJ, Martin RJ, Carlo WA, Fouke JM, Strohl KP, Fanaroff AA. Oral breathing in newborn infants. $\mathcal{F}$ Pediatr 1985; 107: 465-9.

9 Stanescu DC, Perlmutter N, Rodenstein DO. Nasal breathing in infancy is not obligatory. Am Rev Respir Dis 1984; 129: A207.

10 Wohl MEB. Bronchiolitis. In: Chernick V, ed. Kendig's disorders of the respiratory tract in children. 5th Ed. Philadelphia: WB Saunders, 1990: 361-70.

11 Berman S, Simoes EAF, Lanata C. Respiratory rate and pneumonia in infancy. Arch Dis Child 1991; 66: 81-4.

\section{Commentary}

Inability to feed is a common reason for hospitalisation in acute bronchiolitis, particularly in those under the age of 4-5 months. For many years it has been standard practice to maintain hydration and nutrition during the acute phase of the illness, usually less than five days, by initiating nasogastric feeding. The spectre has now been raised that we have been doing these sick infants a major disservice by adding significantly to their work of breathing.

This hypothesis is based on two concepts. Firstly, that the infant has difficulty adapting to nasal breathing in the presence of total or partial nasal obstruction. There is increasing evidence that the ability to commence oral breathing is a maturation factor. A recent study has shown that preterm babies show an increasing ability to adapt so that whereas only $8 \%$ commenced mouth breathing after nasal obstruction at 32 weeks, ${ }^{1}$ this has risen to $28 \%$ at $35-36$ weeks and to $40 \%$ at term. ${ }^{2}$ Information on infants aged 3-6 months is more limited, but certainly suggests that the ability to commence oral breathing in response to total nasal obstruction is very common and that nasal breathing should be considered to be preferential rather than obligatory in infancy, a situation which persists into adult life. The second hypothesis is that the presence of the nasogastric tube will greatly increase upper airway resistance in infants. Although measurements have indicated that in health, the nasal resistance may represent $40 \%$ of the total respiratory resistance, ${ }^{3}$ a recent study using forced oscillation technique in infants with asthma has found that the nasal component represented only $16 \%$ of the total. ${ }^{4}$ It is claimed in the accompanying paper that the use of nasogastric tubes significantly increase the resistance of babies $<2000 \mathrm{~g}$ in body weight. ${ }^{5}$ It should perhaps be pointed out that the same authors could find no evidence of increased work of breathing or resistance in preterm babies over $2000 \mathrm{~g}$ in weight, suggesting that even in these relatively small babies, the presence of a nasogastric tube does not have a significant effect. ${ }^{5}$

It may be that in bronchiolitis the presence of secretions in the upper airways may alter the situation so that the nasal airway becomes more critical. We are exhorted to select the smallest nostril if nasogastric tubes are passed. This would appear to be an unrealistic approach in acute bronchiolitis. A recent study has shown that in infancy a dominant nasal airway is present in only approximately $60 \%$ of individuals. ${ }^{6}$ The most important factor in determining obstruction to breathing in the upper airway in bronchiolitis is likely to be the presence of the secretions.

Obviously, one could pass a nasogastric tube down the nostril that exhibited the least airflow using a strand of cottonwool or tissue paper, but it is a common observation that the pattern of obstruction from secretion can also alter within a few minutes. Should we be continually replacing the nasogastric tubes, chasing the secretions from one nostril to the other?

The two alternative methods for maintaining hydration and nutrition are either to use an orogastric tube or to revert to the intravenous route. Although many newborn babies tolerate oral tubes satisfactorily, most older infants tend to retch and vomit, presumably due to pressure of the tube on the fauces. Orogastric tubes are also more difficult to stabilise so that the risk of aspiration will be greater. The intravenous route does provide a practical alternative, but is more invasive, will not satisfy the infant's hunger and is more likely to lead to over hydration.

In conclusion, I would claim that the case against nasogastric tubes in bronchiolitis is not proved. Obviously, as small a tube as possible should be selected, but it would seem to be appropriate that more studies should be carried out before a form of treatment that has proved satisfactory for many years is rejected.

A D MILNER

St Thomas's Hospital

Lambeth Palace Road, London SE1 7EH

1 Miller MJ, Carlo WA, Fanaroff AA, Martin RJ. Effect of maturation on oral breathing in sleeping infants. $\mathcal{F}$ Pediatr 1986; 109: 515-9.

2 Miller MJ, Martin RJ, Carlo WA, Fouke JM, Strohl KP, Fanaroff AA Oral breathing in newborn infants. $f$ Pediatr $1985 ; 107 ; 465-9$.

3 Polgar G, Kong GP. The nasal resistance of newborn infants. f Pediatr 1965; 67: 557-67.

4 Desager KN, Willemen M, Van Bever HP, De Backer W, Vermeire PA. Evaluation of nasal impedance using the forced oscillation technique in infants. Pediatr Pulmonol 1991; 11: 1-7.

5 Greenspan JS, Wolfson MR, Holt WJ, Shaffer TH. Neonatal gastric intubation: differential respiratory effects between nasogastric and orogastric tion: differential respiratory effects betwe
tubes. Pediatr Pulmonol 1990; 8: 254-8.

6 Martin RJ, Miller MJ, Siner B, DiFiore JM, Carlo WA. Effects of unilateral nasal occlusion on ventilation and pulmonary resistance in infants. $\mathcal{F} A p p l$ Physiol 1989; 66: 2522-6. 